\title{
NATUREZA-ORNAMENTO: A ARQUITETURA MORFOGENÉTICA DO ART NOUVEAU CONTEMPORÂNEO ${ }^{1}$
}

\author{
Diogo Ribeiro Carvalho
}

DOI: 10.5752/P.2316-1752.2017v24n34p10

\section{Resumo}

O presente ensaio objetiva entender a extensão das noções sobre a natureza nos fundamentos arquitetônicos do movimento Art Nouveau no final do século XIX e início do XX. A partir da conexão de conceitos correntes à época como empatia, abstração, evolucionismo, naturalismo, morfogênese e emergência - pretende-se demonstrar como o complexo natureza-ornamento é traduzido do Art Nouveau para a contemporaneidade, enquanto alternativa crítica ao racionalismo.

Palavras-chave: Natureza. Ornamento. Art Nouveau. Morfogênese. Emergência.

\footnotetext{
1. Este artigo toma por base investigação em andamento no doutoramento de Diogo Ribeiro Carvalho, no Programa de Pós-graduação em Arquitetura e Urbanismo (NPGAU) da Universidade Federal de Minas Gerais (UFMG), sob orientação de Stéphane Huchet. 2. Arquiteto e Urbanista pela UFMG, mestre em Arquitetura e Urbanismo pela UFMG, doutorando do Programa de Pós-graduação em Arquitetura e Urbanismo (NPGAU) da UFMG. Professor do Departamento de Arquitetura da PUC Minas. Contato: crdiogo@gmail.com
} 
NATURE-ORNAMENT:THE MORPHOGENETICARCHITECTUREOFCONTEMPORARYARTNOUVEAU

\section{Abstract}

This essay aims to understand the extent of the influence of notions about nature in the architectural foundations of the Art Nouveau movement in the late nineteenth and early twentieth centuries. The connection of current concepts at the time such as empathy, abstraction, evolutionism, naturalism, morphogenesis and emergence - intends to demonstrate how the nature-ornament complex is translated from Art Nouveau to contemporaneity, as a critical alternative against rationalism.

Keywords: Nature. Ornament. Art Nouveau. Morphogenesis. Emergence.
NATURALEZA-ORNAMENTO: ARQUITECTURA MORFOGENÉTICA DEL ART NOUVEAU CONTEMPORÂNEO

\section{Resumen}

Este estudio tiene como objetivo comprender el alcance de las nociones de la naturaleza en las bases arquitectónicas del movimiento Art Nouveau de finales del siglo XIX y principios del XX. A partir de la conexión de los conceptos actuales en el momento - como la empatía, la abstracción, la evolución, el naturalismo, la morfogénesis y la emergencia - está destinado a demostrar cómo el complejo naturaleza-ornamento se traduce del Art Nouveau hasta el contemporáneo, como una crítica alternativa de racionalismo.

Palabras-claves: La naturaleza. Adornos. Art Nouveau. Morfogénesis. Emergencia. 
O desejo de entender forma em termos de formação é uma das razões que a atenção que os arquitetos digitais dão aos desdobramentos científicos recentes, por exemplo na teoria dos sistemas dinâmicos ou na genética que imprime uma ênfase na propriedade de emergência [emergence] concebida como uma capacidade de auto-organização que opera por toda a natureza (PICON, 2010, p.63).

\section{Introdução}

O teórico francês Antoine Picon (2010; 2013) relaciona a presença do ornamento na contemporaneidade com a evolução da relação que os arquitetos passaram a ter com digital e com a ciência: a metáfora da natureza. A proposta deste artigo é elucidar como o Art Nouveau, entre o final do século XIX e início do XX, informou a constituição da condição ornamental da arquitetura atual. Nossa hipótese é em parte derivada da hipótese evolucionária do teórico e historiador do ornamento Owen Jones (1809-1874): a de que um estilo poderia surgir do ornamento, isto é, um sistema ou uma lógica geral poderia ser construído a partir de teste e evolução de um sistema de menor escala, mas cuja complexidade é transmitida ao longo do tempo. Isso significa que experimentações ornamentais poderiam gerar um sistema ornamental maior e mais complexo, que poderia chegar a uma espacialidade total. A arte decorativa e o ornamento do Art Nouveau passam a ser um sistema 
espacial completo particularmente com Antoni Gaudí, um sistema arquitetônico fundado na lógica da natureza. Se a natureza, hoje complexa, é fundamento para a arquitetura atual, é plausível considerar a possibilidade da configuração de sistemas ornamentais reguladores da forma.

O ensaio seguirá por três tópicos que delinearão a discussão: "Empatia e Abstração"; "O Complexo NaturezaOrnamento"; "Emergência e arquitetura morfogenética"; seguidos da conclusão.

\section{Empatia e abstração}

As investigações estéticas no âmbito das sensações tiveram grande força a partir do século XVIII, com discursos de Immanuel Kant (1724-1804) e Edmund Burke ${ }^{3}$ (1729-1797), e ao final do século $X I X$ e início do $X X$ já se via uma série de discussões nos meios filosófico, artístico, arquitetônico e nos primórdios da psicanálise. Uma das contribuições seminais para o assunto foi a tese de doutoramento do historiador de arte Wilhelm Worringer (1881-1965) - Abstrak-

3. Burke publica em 1757 o tratado de estética A Philosophical Inquiry into the Origin of Our Ideas of the Sublime and Beautiful. Em 1759 teve sua segunda edição lançada, com a reafirmação de seus conceitos básicos e o acréscimo de novos exemplos e considerações, em resposta às críticas publicadas, além de uma introdução ao gosto e uma seção inteira (Poder). É provável que tal introdução tenha sido decorrente do ensaio de David Hume (1711-1776), On Taste, publicado apenas dois meses antes do Enquiry. Kant publica em 1790 a "Crítica do Juízo", estabelecendo as bases da estética fenomenológica de Hegel anos depois. 
tion and Einfühlung ${ }^{4}$ - que teoriza sobre a lógica dualista de manifestação da arte e particularmente do ornamento ao longo da história, ora fundando-se na abstração, ora na empatia; modos que dependeriam das aspirações dos homens de cada época e lugar, uma espécie de espírito do tempo, mas que viria de urgência e necessidade viscerais. Worringer (1997), dois anos antes da publicação de "Ornamento e Crime" de Adolf Loos (1870-1933), entende que a estética da modernidade passa da consideração da arte do ponto de vista do artista para a impressão do sujeito que contempla a obra, isto é, para a consideração do efeito que uma obra de arte, um objeto ou um espaço têm sobre as pessoas. Esse movimento do objetivismo ao subjetivismo estético no final do século XIX e início do XX culmina na teoria da empatia, formulada fundamentalmente pelo filósofo alemãoTheodor Lipps (1851-1914). O objetivo principal de Worringer com seu tratado era demonstrar que o modo da estética da modernidade, que se fundamenta no conceito de empatia, é inaplicável em diversas circunstâncias da história da arte. A empatia seria apenas um dos polos da lógica da produção artística; o outro seria a abstração.

Nós consideramos esse contrapolo uma estética que provém não da necessidade de empatia do homem, mas da sua necessidade de abstração. Assim como a

4. Escrita concluída em 1906 e publicada em 1908. Traduzido para o inglês como Abstraction and Empathy: A Contribution to the Psychology of Style, e para o espanhol como Abstracción y Naturaleza. 
necessidade de empatia como uma pressuposição da experiência estética possui sua gratificação na beleza do orgânico, a necessidade de abstração tem sua beleza na negação da vida do inorgânico, no cristalino ou, em termos gerais, em toda lei e necessidade abstratas (WORRINGER, 1997, p.4) (Tradução nossa).

Nessa definição relacional de empatia e abstração, Worringer faz uma associação entre empatia e as formas orgânicas, entendidas por vivas, e abstração e as formas inorgânicas, entendidas por não-vivas. O autor recupera a teoria estética de Lipps em que se entende que a atividade perceptiva se torna prazer estético no caso da empatia positiva, em que há uma congruência entre "minhas tendências naturais para auto-ativação e a atividade demandada por mim pelo objeto sensual" (WORRINGER, 1997, p.7). É dessa noção tradicional sobre experiência estética que resultam as definições de belo e feio ${ }^{5}$. Isso indicaria, portanto, a pressuposição da existência do processo de empatia em toda e qualquer criação artística a qualquer tempo. Worringer entende que essa pressuposição somente é válida quando a vontade artística de um povo, em local e tempo específicos, está inclinada para a organicidade da vida, isto

5. É interessante observar que na mesma época da formulação da teoria de Lipps, Edmund Burke já discutia os modos de prazer e dor - consideradas paixões opostas - (prazer positivo, dor positiva, prazer negativo e dor negativa), introduzindo mais variáveis na lógica do gosto - como a categoria do sublime - para além de belo ou feio. 
é, para o naturalismo de modo geral. Contudo, a tese de Worringer é a de que a tendência decorativa abstrata, a vontade de abstração, está na origem de muitos povos e, inclusive, permanece como tendência dominante em momentos de alto desenvolvimento cultural, em especial nos povos orientais 6 .

Não há, portanto, nenhuma relação causal entre a ornamentação orgânica ou abstrata com a evolução cultural dos povos. Haveria, na verdade, predisposições psíquicas, culturais e religiosas para o desenvolvimento de uma ou outra prática decorativa. Worringer (1997, p.15) indica que a précondição para a necessidade de empatia é uma "relação panteística feliz de confiança" entre homem e os fenômenos do mundo exterior, como no caso dos celtas, dos nórdicos e dos gregos com o avançar do tempo. A necessidade de abstração seria o resultado de uma "grande inquietação interna ao homem causada pelos fenômenos do mundo exterior", configurando-se como um "imenso medo espiritual do espaço" (Idem). A comparação de Worringer com o medo físico de espaços abertos, condição patológica identificada ${ }^{7}$ no homem moderno e agravada ao longo dos séculos XIX e XX, é interessante por ambas se desenvolv-

6. Para exemplos que ilustram essa argumentação, cf. JONES, Owen. A gramática do ornamento.

7. Cf. Trabalhos de Georg Simmel (1858-1918) a partir de The Metropolis and Mental Life, de 1903. 
erem por uma agravada racionalização, não só do espaço, mas da vida de modo geral, das relações, das crenças, das motivações.

É exatamente esse senso generalizado e exacerbado de racionalidade que levará Adolf Loos a estabelecer uma relação de causalidade entre um Papua e as ornamentações em seu corpo e seus objetos, indicando que o ato ornamental é indício de atraso cultural. De outra maneira, associa a tatuagem na era moderna com a noção de degeneração, imoralidade e perversão.

Os tatuados que não estão presos ou são potenciais ladrões ou aristocratas degenerados. (...) O homem actual, que na sua ânsia interior besunta as paredes com motivos eróticos, é um criminoso ou degenerado. Aquilo que no Papua e na criança é natural é no homem moderno uma manifestação de degeneração (LOOS, 2004, p.224).

Tal argumentação indica a natureza puritana, moralista e higienista de Loos, a qual foi usada como artifício para militar a favor da evolução cultural humana pela supressão da ornamentação. Pela perspectiva de Worringer, essa posição seria a mais radical dentro da necessidade de abstração que se poderia ter à época, especialmente se se considerar que em momento algum Worringer presumiu a ausência do ornamento, mas uma mudança no modo de sua aparição ao longo da história. A vontade de ornamentar sempre exis- 
tiu, apenas a natureza dessa vontade artística é que variaria de acordo com as aspirações humanas. Esse embate radical de Loos surge à altura da manifestação arquitetônica e artística de seu oposto, a supremacia naturalista que chega ao seu ápice ao final do século XIX: o Art Nouveau que, ao final do século XIX, se mostra como a expressão máxima da vontade de empatia, da preeminência do orgânico sobre o cristalino, do misticismo e do ocultismo sobre o racionalismo. Em última instância, é uma reverência à sabedoria da natureza em detrimento à sabedoria do homem.

A teoria evolucionista de Charles Darwin (1809-1882) é apresentada ao mundo em 1859 com On the Origin of Species, e teve duas repercussões importantes e opostas na arquitetura: (1) o aumento das investigações sobre o mundo natural - muitos arquitetos passaram a ter interesse no estudo da natureza, que se torna uma das principais fontes nos procedimentos criativos do Art Nouveau; (2) a ideia analógica de que se poderia interpretar a história da arquitetura como uma sequência evolutiva garantiu uma série de argumentações para a supressão de estilos arquitetônicos já datados, e do próprio elemento ornamental, em prol de uma arquitetura da modernidade, evoluída e distinta de seus antepassados. O desdobramento da segunda repercussão culmina na atual história da arquitetura moderna. A primeira repercussão é uma das circunstâncias históricas de surgimento do Art Nouveau e de seus desdobramen- 
tos; evidenciados pela organicidade das formas inspiradas em motivos florais, vegetais e animais e pela sua influência no sistema ornamental de Louis Sullivan (1856-1924) - sua teoria do florescimento - no desenvolvimento do conceito de arquitetura orgânica de Frank Lloyd Wright (1867-1959) nos Estados Unidos, por exemplo.

\section{O complexo Natureza-Ornamento}

A lógica estética do Art Nouveau é fundamentalmente naturalista. Contudo, não se trata de uma imitação da natureza como ela é, mas do entendimento de como a forma natural se comporta e da tentativa de criação de um novo mundo orgânico nos objetos, nos espaços interiores e exteriores. A tradução, ou mimese, da natureza nas arquiteturas naturalistas e racionalistas se diferem por dualidades: Empiria versus Racionalidade. Imaginação versus Realidade. Curva versus Reta. Particularidade versus Generalidade. Empatia versus Abstração. Natureza versus Homem. Assim, não só a produção humana é distinta em cada caso, mas também o processo de concepção e a mentalidade que fundamentam as práticas.

O conceito Kunstwollen, ou "vontade artística absoluta", que Worringer (1997, p.9) toma emprestado de Alois Riegl, mostra a importância de distinção entre impulso de imitação da natureza e naturalismo. Enquanto o primeiro nada tem de relação com a arte por, apesar de se tratar de uma 
necessidade primária do homem, ser, em absoluto, uma habilidade; o segundo é um dos modos como a arte pode se manifestar, regida, portanto, não por habilidade, mas por vontade de criação. Isso implica, necessariamente, uma posição ativa do homem. Observando a arte na história, pode-se construir a hipótese de que a ornamentação é a expressão máxima da arte e manifestação da capacidade criadora e interpretativa do homem ${ }^{8}$. Será na segunda metade do século XIX, não só com o Art Nouveau, mas com uma série de publicações de biólogos e evolucionistas, que se reconhecerá cientificamente a lógica formal da natureza como ornamental.

A ideia de tomar emprestado das fontes mais belas da construção e do ornamento [da natureza], de buscar inspiração nos mais belos monumentos concebíveis - a terra, as árvores, as flores, e, lá em cima, o céu - não é mais que o retorno de uma genuína tradição arquitetural (VELDE In DORRA, 1994, p.121).

Ao final do século XIX já era bastante conhecida a "Gramática do Ornamento", publicada em 1856, do arquiteto inglês Owen Jones (1809-1874), que elaborou uma série de princípios do uso do ornamento a partir de estudos da lógica

8. Cf. RIEGL, Alois. Stilfragen: Grundlegungen zu einer Geschichte der Ornamentik (ou em inglês, Problems of style: foundations for a history of ornament), de 1893; e BLOOMER, Kent. The Nature of Ornament: Rhythm and Metamorphosis in Architecture, de 2000. 
ornamental ao longo dos séculos e em culturas distintas. Um dos princípios mais importantes desenvolvidos é o de que "em qualquer período comprometido com a arte, toda ornamentação era enobrecida pelo ideal, e o senso de propriedade nunca era violado por uma representação excessivamente fiel da natureza" (JONES, 2010, p.195). Jones faz tal apontamento no contexto da análise do ornamento no Alhambra, em Granada, Espanha, reconhecendo o ápice da ornamentação moura, resumida no entendimento da lógica na natureza e não em sua cópia.

O alemão Ernst Haeckel (1834-1919) será o biólogo mais importante a construir e defender essa tese a partir da descrição gráfica de inúmeros organismos, inicialmente com a publicação Die Radiolarien, em 1862 - um estudo sobre um grupo de organismos unicelulares microscópicos, os radiolários, de impressionante morfologia ornamental, que evidencia uma composição de complexos padrões de simetria remanescentes de cristais (BREIDBACH In HAECKEL, 2012). Haeckel irá continuar suas investigações segundo a noção de que a morfologia das formas orgânicas é análoga à dos cristais $^{9}$, desenvolvendo o que ele chamou de estereometria orgânica.

Sua ideia era a de que a classificação de formas orgânicas

9. Essa analogia morfológica é particularmente interessante se se considerar o antagonismo proposto por Worringer entre naturalismo e abstração, isto é, entre orgânico e inorgânico ou cristalino. 
iria evidenciar níveis cada vez maiores de complexidade, aparentes nas formas exteriores apenas condicionalmente; entretanto, seu tecido iria gradualmente diferenciando-se no curso da evolução. As células individuais, já estruturadas simetricamente, estão integradas nesse tecido; macroscopicamente, elas podem ser parcialmente descritas em termos estereométricos simples, mas elas exibem uma riqueza de padrões complexos em suas estruturas mais finas. Haeckel interpretou essas séries de formas, definidas por tais descrições, como o resultado de uma história contínua das formas de vida. De acordo com sua interpretação, as estruturas básicas da forma orgânica - no caso, células - organizam-se em configurações gradualmente mais complexas. Contudo, organismos que se originam dessa maneira não permanecem inalterados e, sim, são submetidos a outras diferenciações de suas estruturas por meio de herança ou adaptação. Qualquer espécie de uma árvore filogenética é constituída de acordo com regras adquiridas e conservadas ao longo de seu desenvolvimento (BREIDBACH In HAECKEL, 2012). Esse processo evolucionário, que envolve regras pré-estabelecidas, adaptações necessárias e desenvolvimento, é a base de sua "Lei Biogenética", de 1866.

Essa mesma condição evolucionária é o fundamento da configuração ornamental em arquitetura. A organização do ornamento é rítmica, ou seja, é subordinada a sistemas 


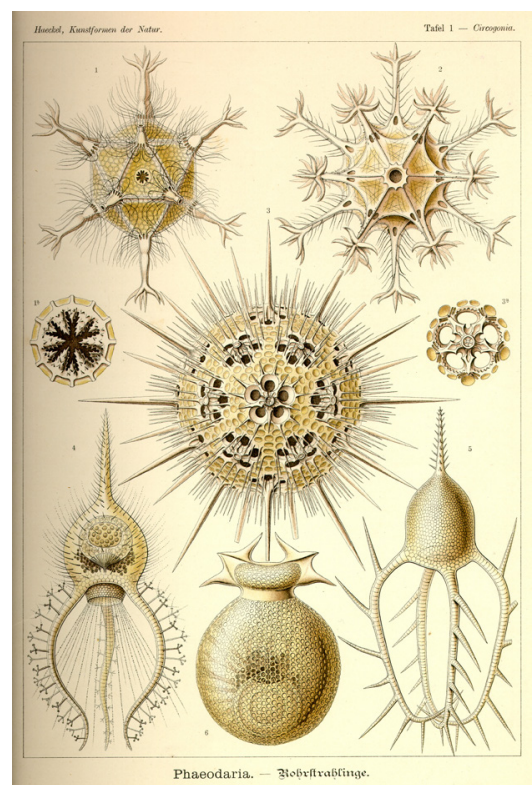

Figura 1 - Classe Radiolária. Plate 1 - Art Froms in Nature (Kunst-Formen der Natur) de Ernst Haeckel. Fonte: Kurt Stüber, Online Library (www. biolib.de). Obra de domínio público.

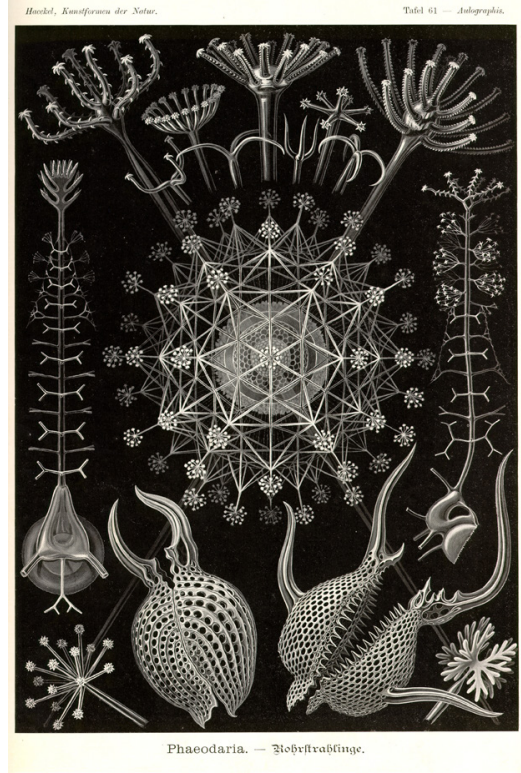

Figura 2 - Classe Radiolária. Plate 61 - Art Froms in Nature (Kunst-Formen der Natur) de Ernst Haeckel. Fonte: Kurt Stüber, Online Library (www. biolib.de). Obra de domínio público.

geométricos e de proporção; o ornamento está sempre em relação a algo - física ou simbolicamente - portanto, trabalha a dinâmica de sua forma por meio de metamorfoses (BLOOMER, 2000).

A influência de Haeckel no movimento Art Nouveau é considerável, pois se estende desde Louis Comfort Tiffany (1848-1933) em Nova lorque, a Joseph Maria Olbrich (18671908) em Viena, ou ainda, aos trabalhos de August Endell (1871-1918) em Munique. A expressão mais monumental 
das formas ornamentais catalogadas pelo biólogo pode ser observada na entrada da Exposição Universal de Paris de 1900, La Porte Monumental Paris, na Place de la Concord, projetada pelo arquiteto francês René Binet (1866-1911). A estrutura, com um grande domo e três arcos, e sua ornamentação são derivadas da forma de vários radiolários, como nassellarium e porodiscida10 (PROCTOR In BINET, 2007). A concepção de tal obra, assim como várias obras Art Nouveau, incorpora motivos de um corpo de um trabalho científico que, até então, não tinha sido considerado para a arquitetura e a ornamentação. Em 1893, o jovem arquiteto Binet começa seus estudos sobre natureza a partir da leitura de vários números do Challenger Expedition"1, disponíveis à época na biblioteca do Museu de História Natural de Paris. Além de Haeckel, haverá diversas influências dos meios científico e arquitetônico que levarão Binet a avançar na hipótese da lógica morfogenética inerente a processos e formas da natureza de servirem de modo e inspiração à arquitetura. René Binet se mostra relevante, não só por ter projetado uma das principais edificações Art Nouveau na exposição de 1900 aos 34 anos, mas também

10. No caso, a descrição gráfica de tais organismos encontra-se nas lâminas 65 e 46, respectivamente, do Report on the Radiolaria (Challenger Report), de 1887. 11. O Challenger Expedition foi uma série de cinquenta volumes publicados entre 1880 e 1895 por um grupo de cientistas que viajou pelo mundo entre 1873 e 1876 a bordo de um navio de guerra inglês convertido em laboratório, H.M.S. Challenger. 
pela publicação, dois anos mais tarde, de Esquisses Décoratives. Mais que um catálogo decorativo ou ornamental que mostra propostas originais de arquiteturas até joias, evidencia o potencial da lógica metamórfica e adaptativa da

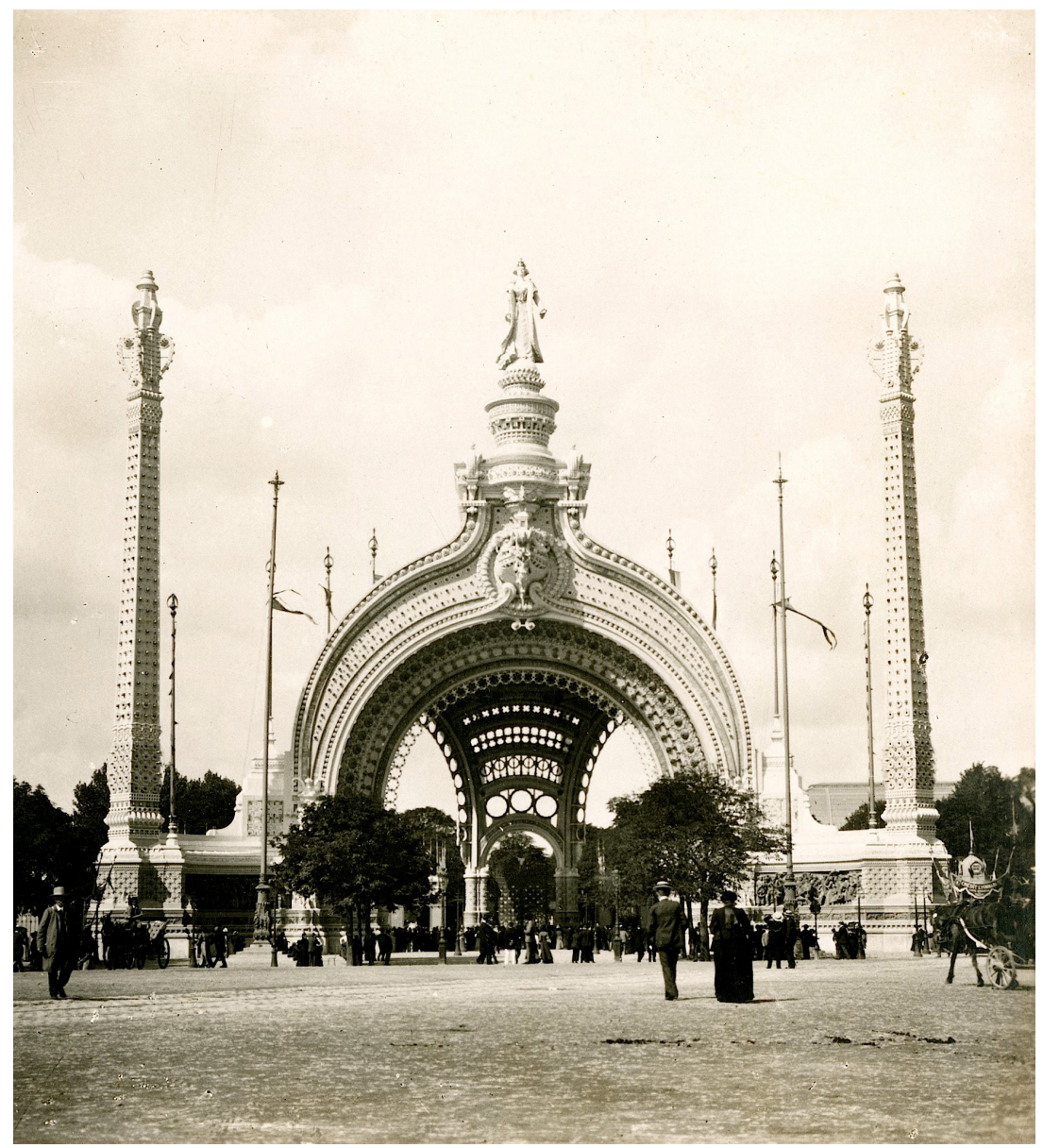

Figura 3 - Porte Monumental, Place de la Concord, Paris, 1900, de René Binet. Fonte: Coleção Digital da National Gallery of Art de Washington, EUA (www. nga.gov). 


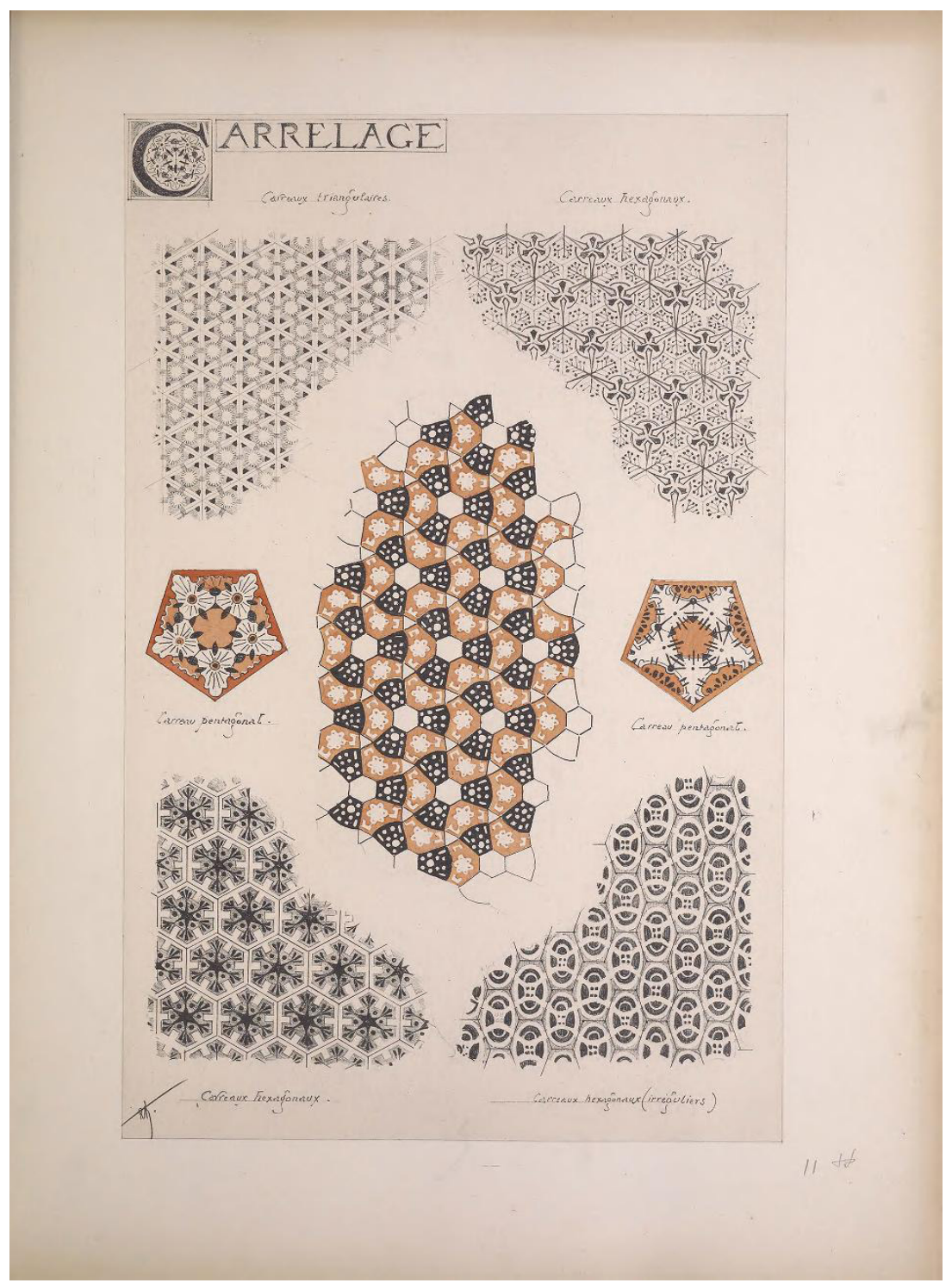

Figura 4 - Ladrilhos de Piso em Esquisses Décoratives, de René Binet. Fonte: Coleção Digital da Biodiversity Heritage Library da Harvard University, (archive. org). Obra de domínio público. 
natureza-ornamento. Trata-se da tentativa de alargamento dos limites da disciplina pelo reconhecimento do potencial de outro campo para geração de novas abordagens espaciais, no caso o caráter evolucionário e ornamental da natureza.

Owen Jones, na última parte da "Gramática do Ornamento", intitulada "Folhas e Flores da Natureza", ao abordar a possibilidade da formação de um novo estilo de arte ou novo estilo de ornamento, mostra sua esperança nos jovens do futuro - no contexto de 1856 - e dedica a eles seu livro, o qual poderia mostrar o potencial de desenvolvimento criativo ao estudar atentamente a ornamentação dos antigos e construir o ornamento a partir dos princípios formais e de crescimento evidentes na natureza. Reconhecendo a condição de cópia em que a arquitetura estava inserida à época, com os revivals estilísticos historicistas, Owen Jones (2010, p.473-474) faz uma proposição radical e inverte o pressuposto da origem dos estilos, baseada no mito da "invenção súbita" e completa de uma lógica estética: "Vemos razão para acreditar que um novo estilo de ornamento pode ser produzido independentemente de um novo estilo de arquitetura, e, além de mais, que seria um dos meios mais imediatos de chegar a um novo estilo".

As principais características de uma construção que formam um estilo são, em primeiro lugar, os meios de apoio, em segundo, os meios de cobrir o espaço entre 


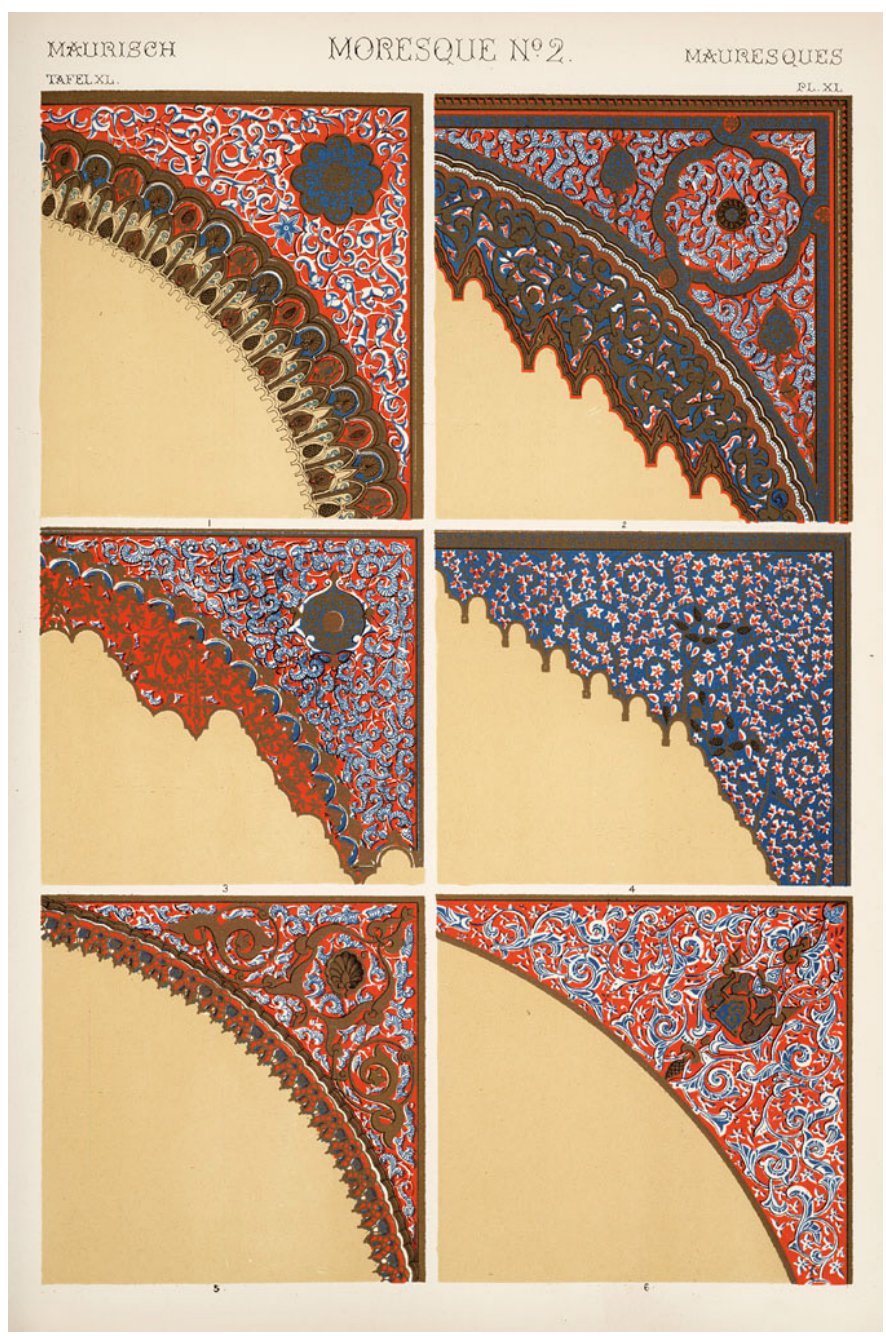

Figura 5 - Lâmina XL de "A Gramática do Ornamento", de Owen Jones, mostra os tímpanos dos arcos do Alhambra, em Granada. Da esquerda para a direita e de cima para baixo: do arco do Pátio dos Leões; da entrada do Divã da sala das Duas Irmãs; da entrada do Pátio dos Leões do Pátio da Alberca; da entrada do Pátio da Alberca da Sala da Barca; dos arcos da Sala dos Reis (as duas imagens de baixo). Fonte: Digital Library for the Decorative Arts and Material Culture da University of Wisconsin-Madison. Obra de domínio público. 


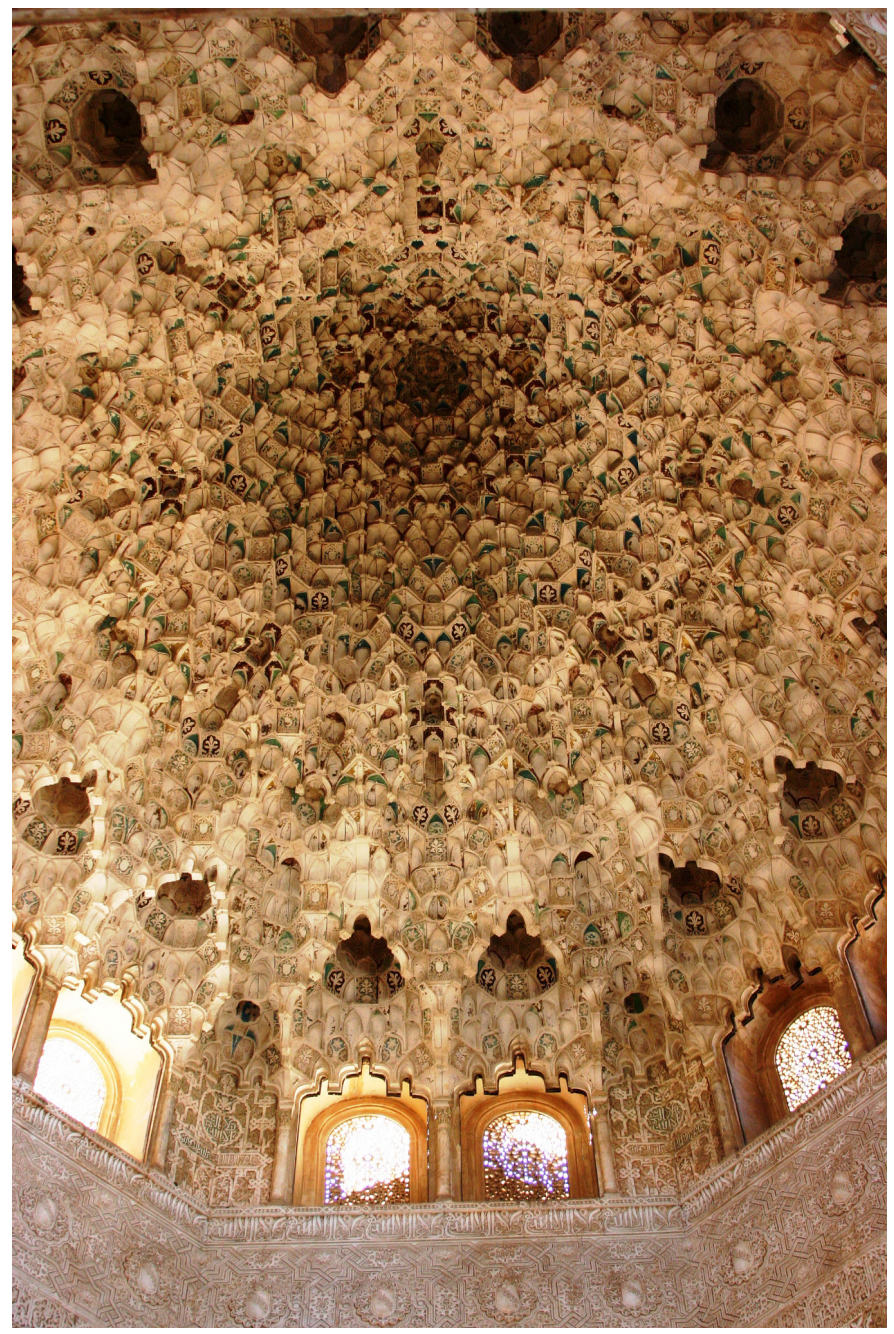

Figura 6 - Cúpula da sala das duas Irmãs evidenciando o trabalho ornamental espacial pela técnica das muqarnas. Fonte: @ José Luiz Bernardes Ribeiro / CCBY-SA-3.0 - Licença Creative Commons.

os apoios e, em terceiro, a formação do teto. É a decoração dessas formas estruturais que confere as características ao estilo, e todas seguem tão naturalmente 
uma após a outra que a invenção de uma vai determinar o resto (JONES, 2010, p.474-475).

Jones entendia que os ornamentos eram acessórios para a arquitetura, ao mesmo tempo em que os considerava a alma do edifício. A arte decorativa e o ornamento do Art Nouveau passam a ser um sistema espacial completo particularmente com Antoni Gaudí, um sistema arquitetônico fundado na lógica da natureza. Enquanto o mundo natural serve de inspiração e referência para toda produção de design dentro do movimento, Antoni Gaudí toma a natureza como fundamento, fundação, origem da vida. Sua religiosidade e espiritualidade encaminham seu pensamento em direção à origem divina do mundo, da natureza e do homem, o que o impele a imprimir um "sentido cósmico" (BERGÓS, 1954, p.95) aos seus espaços, da lógica geral formal e estrutural até os detalhes de materiais, figurações e inscrições. Por isso, Gaudí constrói para si uma percepção diferenciada, outro modo de olhar as coisas do mundo, talvez de forma semelhante ao conceito de organicidade de Frank Lloyd Wright.

Este conceito de espaço interior, a primeira e mais vasta integridade é o primeiro grande recurso. É também a verdadeira base para o significado da forma como um todo. Acrescente-se para uma maior clareza conceitual que está na natureza de qualquer edifício orgânico desenvolver-se a partir de seu local, ainda que a interação global esteja já implícita no primeiro recurso. Assim 
emerge um organismo do solo em direção à luz sendo esse mesmo solo considerado parte integrante do edifício. Teremos então, em primeiro lugar, o novo edifício como ente Orgânico. Um edifício tão digno como o é uma árvore na natureza (WRIGHT, 2010, p.220).

Roberto Pane, Ignasi de Solà-Morales e outros reconhecem um movimento gradual da obra de Gaudí em direção ao naturalismo, evidente em suas obras de maturidade como no Parque Güell (1900-1914), na Casa Batlló (1904-1906), na Casa Milà (1906-1910) e no Templo da Sagrada Família (1883-1926). Contudo, pode-se construir a hipótese de que a natureza sempre esteve presente enquanto fundamento estético-construtivo nas configurações do arquiteto, desde seus primeiros trabalhos na Casa Vicens (1883-1888), na Casa El Capricho (1883-1885) e na Quinta Güell (1884-1887). Essas edificações são marcadas pela experimentação estilística com o gótico e em especial o Mudéjar, uma mistura hispano-mulçumana, característica exclusiva de certas partes da Península Ibérica. Durante seu tempo de estudante, o livro de Owen Jones "Plans, elevations, sections and details of the Alhambra" teve grande influência sobre Gaudí. O entendimento profundo da arte e arquitetura Mudéjar possibilitou tanto a produção de edifícios idiossincráticos e regionalistas, próprios ao lugar, como um pensamento arquitetônico que trabalha dialeticamente a figuração e a abstração. Jones (2010) explica que os árabes e mouros eram proibidos por suas crenças de representar figurativa- 


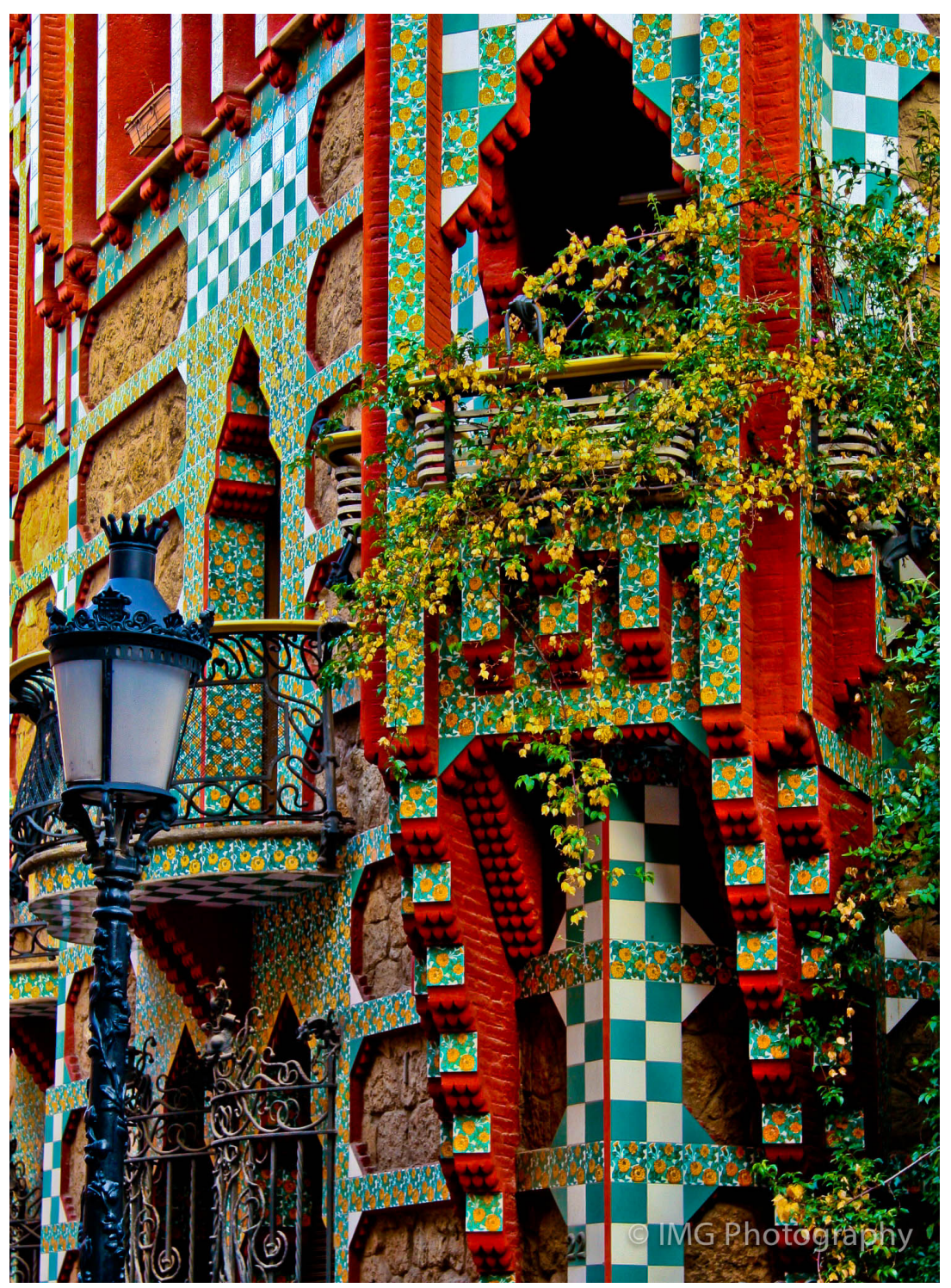

Figura 7 - Referência mudéjar da Casa Vicens de Gaudí. Fonte: @ lan Gampon / CC BY-ND 2.0 - Licença Creative Commons. 


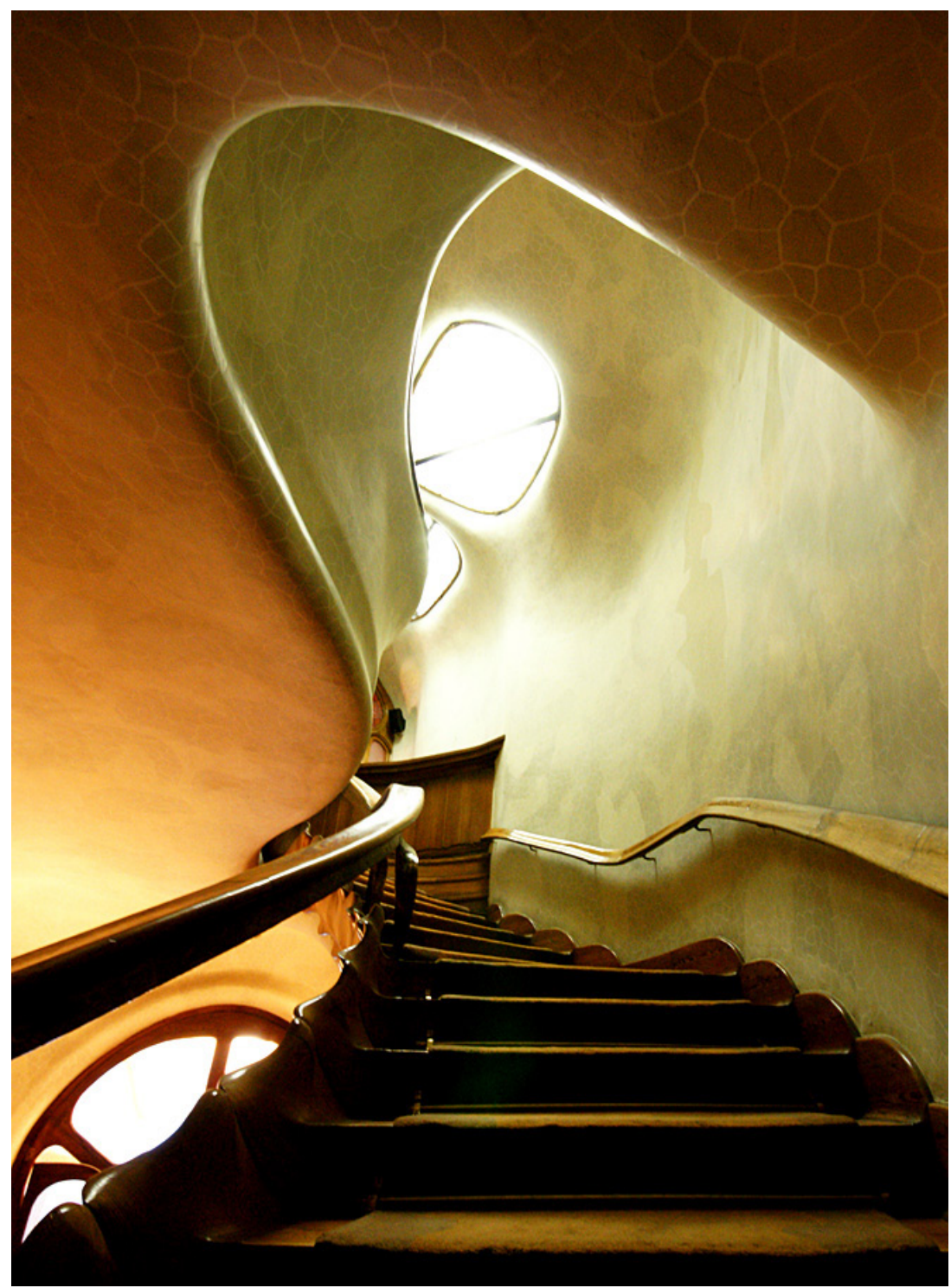

Figura 8 - Organicidade espacial em escada na Casa Batlló de Gaudí. Fonte: () Chong Ming / CC-BY-AS 3.0 - Licença Creative Commons. 
mente as formas vivas, o que os levou a interpretar a lógica geométrica e de crescimento das coisas da natureza e atingir a mais alta perfeição na sua ornamentação. Nos padrões geométricos complexos dos ornamentos, estavam imbricadas as leis naturais e, por conseguinte, a lei divina suprema.

Se Owen Jones julgava o ornamento mouro como o mais perfeito, John Ruskin considerava a arquitetura gótica ${ }^{12}$ como a mais elevada até então, uma posição claramente anticlássica. Sejam pelas circunstâncias geográfica e cultural, sejam pelas influências exteriores, tais modos de ver a arquitetura terão impactos enormes na formação de Gaudí e na construção de sua prática. No recente livro de Lars Spuybroek, "The Sympathy of Things,"de 2011, o autor discute as seis características do gótico, a partir do "The Nature of Gothic" de Ruskin, que se pode transformar em modos de interpretação da arquitetura de Antoni Gaudí: (1) Selvagem ("Salvageness"), que se relaciona a certa ideia de brutalidade, um termo pitoresco, especialmente representando as imperfeições relacionadas com a execução de um projeto pelos operários e artesãos; (2) Mutabilidade ("changefulness"), que diz de um sentido de variedade no design, exemplificado na multiplicidade de variações das curvaturas de molduras, dos rendilhados das janelas, das malhas de nervuras das abóbadas; (3) Naturalismo ("Natu-

12. Cf. também "Form Problems of the Gotic", de Wilhelm Worringer, publicado originalmente em 1910. 
ralism"), que diz da intensa afeição dos operários góticos pelas folhagens vivas e pela natureza de modo geral, que é traduzida nos ornamentos e esculturas - cada folha, galho, nuvem ou pedra são únicos e com suas personalidades; (4) Grotesco ("Grotesqueness"), que ocorre em extensão ao Selvagem, tendo a função de estimular a imaginação e mostra-se na presença de figuras monstruosas e de gárgulas; (5) Rigidez ("Rigidity"), que diz da interpretação da lógica estrutural gótica como um sistema ativo de suporte e transferência de cargas, análogo aos ossos de um membro ou às fibras de uma árvore; (6) Redundância ("Redudan$c y^{\prime \prime)}$, que diz de uma acumulação de detalhes, elementos e ornamentações, que expressaria uma profunda simpatia pela riqueza do mundo físico (SPUYBROEK, 2011, p.13-16).

A fusão das características do Gótico com as do Mudéjar corrobora a possibilidade que Owen Jones proferia sobre o surgimento de um modo arquitetural por meio de um sistema ornamental. Na arquitetura dos mouros, a decoração não só nasce naturalmente da construção, como "a ideia construtiva é executada em cada detalhe da ornamentação da superfície" (JONES, 2010, p.187). Todas as linhas ornamentais surgem umas das outras gradualmente, de modo a torná-las interdependentes para o efeito total contínuo; seu desenho, assim como a percepção do macro ao microscópico de uma árvore ou uma folha, possui uma sucessão de lógicas formais em escalas compositivas do 
todo às partes e sempre surge de um ramo ou haste principal. Trata-se de um entendimento do dinamismo de desenvolvimento de um organismo vivo, de uma continuidade e transformação formal natural.

A noção de continuidade em Gaudí é para além de uma composição de linhas ou planos sequenciais. São espaços fluidos e orgânicos como a natureza e o corpo. Uma arquitetura selvagem sugere um crescimento espontâneo e indomável, algo entre o natural e o não-natural construído; cuja mutabilidade está tanto nos detalhes quanto na dinâmica espacial e formal do lugar, como um movimento estático; bela, sublime e grotesca simultaneamente, uma arquitetura com espaços oníricos e fantásticos, em que a cada dobra, reentrância ou passagem há uma surpresa. Trata-se de uma arquitetura que tende para a organicidade constitutiva dos seres vivos, que também é específico e idiossincrático a cada circunstância.

O conceito ruskiano que sintetiza tanto suas prerrogativas quanto as de Gaudí acerca da criação de espaços seja o da Arquitetura Viva ("Living Architecture"); uma arquitetura que teria "sensações em cada centímetro seu" e acomodaria cada necessidade arquitetural do mesmo modo como os elementos, proporções e provisões de um organismo vivo (RUSKIN, 1989, p.160). Trata-se de um conceito obscuro e de difícil apreensão, apresentado e pouco desenvolvido na "Lâmpada da Vida", mas que tem relações muito próximas 
à noção de Empatia de Worringer. A categoria Arquitetura Viva pressupõe a vontade de empatia do espaço para suscitar o movimento de retorno da percepção do corpo e da mente de quem o experimenta. No texto de Ruskin, termos como "substância" e "energia" são postos a caracterizar algo próprio e constituinte de um determinado espaço. Poder-se-ia falar em energia vital de um espaço - comparável à "beleza vital em estética, poder vital nas plantas, força vital nos organismos, e à vitalidade de um corpo ou uma nação" (SPUYBROEK, 2011, p.339) - o que conecta ética e estética e implica uma visão da vida fundada no poder criativo que produz tanto formas animadas como inanimadas. O termo "energia vital", vinculado à arquitetura, esteve em desuso até pouco tempo - fundamentalmente por ter sido abolida do vocabulário racionalista e, por conseguinte, tomada como irrelevante na maioria das instituições de ensino - e ressurge sob a categoria de "emergência" como fundamento máximo da arquitetura paramétrica e morfogenética corrente.

\section{Emergência e arquitetura morfogenética}

O termo "emergência" - "emergence,"em inglês, do verbo "emergir" - foi primeiramente utilizado na filosofia pelo inglês George Henry Lewes (1817-1878), em "Problems of Life and Mind" (1875), para definir o fenômeno do aparecimento de novas qualidades em um sistema físico quando 
da sua passagem de um nível de complexidade para outro, que a princípio não poderiam ser atribuídas às propriedades dos seus elementos constituintes. Um pressuposto, portanto, era que o todo é bem mais que a soma das partes que o constituem.

O termo foi bem aceito à época pela escola inglesa na filosofia e pelas ciências químicas e biológicas. A maior parte dos biólogos, até o final do século XIX, eram "vitalistas" e defendiam a noção de que os organismos vivos possuíam uma energia, ou essência vital, que os animava e impelia seu desenvolvimento. Essa visão era bem distinta dos físicos ortodoxos, que entendiam os seres vivos como semelhantes a máquinas altamente sofisticadas, cujo novo comportamento a cada nível de complexidade era explicável pelas leis básicas da física operando em nível molecular. Os emergentistas, portanto, negavam tanto a existência de uma energia vital como a explicação mecanicista da física reducionista (DAVIES In CLAYTON, 2006). Mas, assim, uma das questões fundamentais passou a ser a própria condição de "estar vivo", mesmo que nenhum átomo individualmente em um organismo estivesse vivo.

Apesar de o termo ter surgido ao final do século XIX, o filósofo fundamental proponente das teorias emergentistas foi G. W. F. Hegel (1770-1831), com sua filosofia da consciência. A "Fenomenologia do Espírito" (1807) oferece uma ontologia temporalizada, cuja categoria do "devir" é 
operativa para o sistema da vida, sintetizado na tríade "ser, não-ser, devir". A oposição entre o ser e o nada é estática e restrita, mas, se postos no tempo, exigem a consideração de um "vir a ser", do processo de sua autoconfirmação. Isso significa que o ser em si não significa nada, pois o ser está sempre em processo que, mesmo sujeito a influências externas, é fundamentalmente controlado por disposições internas, por exemplo, pela consciência. Essa filosofia do processo influenciou uma geração de filósofos, como o americano William James (1842-1910), o francês Henri Bergson ${ }^{13}$ (1859-1941) e o inglês Alfred North Whitehead (1861-1947).

A filosofia do organismo busca descrever como dados objetivos gradualmente se transformam em satisfação subjetiva, e como ordem nos dados objetivos provê intensidade na satisfação subjetiva. Para Kant, o mundo emerge do sujeito; para a filosofia do organismo, o sujeito emerge do mundo - um "superjecto" ao invés de um sujeito. A palavra "objeto" refere-se à entidade que é potencialmente uma componente da sensação, e a palavra "sujeito" refere-se à entidade constituída pelo processo da sensação, incluindo esse próprio processo (WHITEHEAD, 1978, p88).

13. Sua posição antimecanicista e antirreducionista em relação à ciência, assim como os conceitos de tempo como duração e de intuição como conhecimento - a apreensão imediata da realidade pela "coincidência" com o objeto - foram determinantes para as abordagens da experiência a partir do corpo e da sensação em Deleuze e Didi-Huberman, por exemplo. 
O termo "emergência" e suas implicações na ciência foram tomados como irrelevantes com os avanços científicos até a metade do século $X X$, que explicaram muitas propriedades da matéria e da vida pela elucidação da estrutura fundamental da matéria (na física de partículas - atômicas, nucleares, subatômicas - e na mecânica quântica) e da base molecular da biologia. Um dos principais investigadores emergentistas no início do século XX foi D Arcy Thompson (18601948) com o trabalho "On Growth and Form" (1917), no qual argumenta que as formas de plantas e animais poderiam ser entendidas em termos de matemática pura, isto é, da tradução matemática das geometrias naturais presentes nas dinâmicas de crescimento/desenvolvimento e nos processos físicos. Thompson explica as leis que regem a dimensão dos organismos e seu crescimento, a estática e a dinâmica em células e tecidos, incluindo os fenômenos de agrupamento geométrico, membranas sob tensão, simetrias e divisão celular. Explica matematicamente como funcionam as estruturas geodésicas de esqueletos em organismos simples, já registradas por Haeckel desde a década de 1860. Thompson concebia a forma não como algo pronto, mas como um produto de forças dinâmicas que ocorrem em forma de fluxos de energia e de fases de crescimento, semelhante ao pensamento de Ruskin sobre a natureza. O livro teve sua segunda edição em 1942 e a terceira em 1991, quando se volta a haver interesse em recuperar as 
origens do estudo sobre morfogênese.

$\mathrm{O}$ advento das ciências da complexidade desestabilizou as concepções físico-mecânicas que até então se tinham do mundo. Mais que a coexistência entre caos e ordem na natureza, a noção de derivação da ordem a partir de sistemas caóticos, não-lineares e auto-organizados (autopoiésis) reativou a relevância do conceito de emergência não só na ciência, mas na filosofia, na teoria dos sistemas, na arte e na arquitetura. O emitente físico inglês Paul Davies (In CLAYTON, 2006, p.xi) explica que o uso de simulações computacionais, desde a década de 1960, como uma ferramenta experimental de modelagem de sistemas complexos possibilitou o entendimento de que muitos fenômenos no universo não podem ser previstos apenas com um grupo de equações dinâmicas, mas "são descobertos apenas pelo estudo sistemático das soluções na forma de simulações numéricas".

O conceito de autopoiesis ${ }^{14}$ - "auto-formação" - tem sido caro para arquitetos interessados em desenvolver ou aplicar processos generativos para a forma e desde 1980 é o

14. O arquiteto Patrik Schumacher (1961-), sócio em Zaha Hadid Architects, é o principal articulador, promotor e teórico do parametricismo em arquitetura e emprega o termo "autopoiesis" em seu tratado de mais de 1000 páginas, "The Autopoiesis of Architecture," publicado em dois volumes: "A New Framework for Architecture" (2010) e "A New Agenda for Architecture" (2011). Schumacher irá considerar a disciplina "arquitetura" como um sistema fechado, auto-referencial. As implicações dessa posição serão discutidas nesse capítulo ainda. 
conceito fundamental da morfogênese. O termo foi cunhado pelos neurobiólogos chilenos Humberto Maturana (1928-) e Francisco Varela (1946-2001) com o livro "Autopoiesis and Cognition: the realization of the living "15, no qual propõem uma teoria dos sistemas vivos em que eles são considerados sistemas fechados. O projeto, enquanto um sistema fechado, se desenvolve a partir dos parâmetros internos a ele, ou seja, das regras que o arquiteto/designer/ artista escolheu ao seu critério para condicionar e controlar a geração da forma. Enquanto sistema complexo, de muitas variáveis, o uso de softwares paramétricos tem sido ferramenta determinante. O sucesso ou insucesso do sistema dependerá, não só dos parâmetros delimitados, mas do modo como se irá lidar com eles.

No âmbito da arquitetura, em 1969, Gordon Pask publica "The Architectural Relevance of Cybernetics," na revista Architectural Design, incitando os arquitetos a começar a considerar o espaço construído como um organismo que se adapta a circunstâncias, responde a estímulos e evolui de acordo com princípios de inteligência artificial. Pask (In SPILLER, 2002, p.78) critica a indiferença dos arquitetos com os desdobramentos futuros que seus projetos po-

15. O livro é dividido em duas partes: "Biology of Cognition" e "Autopoiesis: the organization of the living." Essa segunda parte já havia sido publicada no Chile em 1972 sob o título "De Maquinas y Seres Vivos," mas o termo autopoiesis ainda não tinha sido criado, apesar das suas implicações estarem desenvolvidas. 
dem ter e invoca a responsabilidade ética de garantir uma evolução "saudável e não cancerígena" da microescala às dimensões urbanas e regionais. Pask especula sobre os potenciais dos projetos assistidos e direcionados por computador e aponta a necessidade de articulação da arquitetura com outras disciplinas para a construção de visões adequadas e amplas do que viria a ser uma arquitetura evolucionária e, sobretudo, para uma "formulação sistemática da maneira como a arquitetura atua enquanto controle social" (PASK In SPILLER, 2002, p.80). Enquanto um dos principais formuladores da cibernética de segunda ordem e da "Teoria Conversacional", Pask preocupa-se com a dinâmica relacional entre a ambiência e as pessoas, isto é, sobre as circunstâncias, os modos e os graus de controle de cada entidade, uma vez que assumem a dupla condição de controladores e controlados dentro de um sistema autoorganizador. A repercussão de Pask na cultura arquitetônica foi enorme e à época influenciou arquitetos como Cedric Price, John Frazer, o grupo Archigram, Buckminster Fuller, Yona Friedman, Christopher Alexander, Nicholas Negroponte e alunos da Architectural Association, instituição com a qual tinha contato próximo.

Da mesma maneira que a influência de Pask foi grande, os modos como os arquitetos interpretaram suas ideias e construíram as suas próprias são também os mais diversos. Um dos desdobramentos importantes foi a contribuição de 
John Frazer (1945-) como pesquisador e docente em diversas instituições de ensino, e em especial pela influência de seu livro seminal "An Evolutionary Architecture,"lançado em 1995 junto a uma exposição com mesmo nome na London Architectural Association. Tratava-se da proposta de um modelo natural para a arquitetura, desenvolvida a partir da investigação sobre modelagem digital de morfogêneses naturais e potenciais aplicabilidades no processo de projeto e de experimentos práticos realizados com seus alunos no estúdio de projeto "Diploma Unit 11", conduzidos com Julia Frazer, entre 1989 e 1996.

Uma Arquitetura Evolucionária investiga processos fundamentais de geração da forma em arquitetura, postos em paralelo a uma vasta pesquisa científica por uma teoria da morfogênese no mundo natural. Ela propõe o modelo da natureza como força geratriz da forma arquitetônica. O impressionante poder criativo e de prototipia sem limites da evolução natural são reproduzidos por meio de modelos arquitetônicos virtuais que respondem a variações ambientais. (...). Arquitetura é considerada como uma forma de vida artificial sujeita, como o mundo natural, aos princípios da morfogênese, de códigos genéticos, de replicação e de seleção. 0 objetivo de uma arquitetura evolucionária é alcançar no ambiente construído o comportamento simbiótico e o equilíbrio metabólico característicos do ambiente natural (FRAZER, 1995, p.9).

Do ponto de vista das teorias da emergência, uma das prin- 
cipais questões de que hoje se ocupam a biotecnologia e a bioética é delimitar o limiar entre a matéria viva e a nãoviva: quando um agrupamento de átomos, moléculas ou elementos químicos transmutam de um estado inorgânico para atingir uma condição mais complexa e animada? Se o que se tem em comum entre Gaudí e Frazer é o desejo de animar a arquitetura, consegue-se perceber lógicas de pensamento semelhantes sobre formações paramétricas derivadas de morfogêneses naturais.

O matemático Benoit Mandelbrot (1924-2010), pioneiro nas teorias da complexidade, escreve em 1983 "The Fractal Geometry of Nature"16. Mandelbrot inicia seu livro com uma provocação aos matemáticos euclidianos que resumiram suas investigações nas formas regulares e simples. O que o impelia naquele empreendimento era a inabilidade dos matemáticos de "descrever o formato de uma nuvem, uma montanha, uma linha costeira ou uma árvore. Nuvens não são esferas, montanhas não são cones, linhas costeiras não são círculos e a casca do tronco da árvore não é lisa,

16. Trata-se da terceira edição em inglês, revisada, reescrita e aumentada, que recebeu o título: "The Fractal Geometry of Nature." Segundo o autor, essa edição substitui a primeira versão em inglês, "Fractals: Form, Chance and Dimension," de 1977, que, por conseguinte, substituiu a primeira versão em francês, de 1975, "Les Objects Fractals: Forme, Hasard et Dimension". A inclusão da dimensão "natureza" era um indício da necessidade de aprofundamento científico em dimensões inexploradas, mas reais, do mundo natural, do universo. Apesar de Mandelbrot ter publicado inúmeras pesquisas anteriores a essa publicação, é ela que marca para a ciência formal a origem da Teoria do Caos. 
nem o raio viaja em linha reta" (MANDELBROT, 1983, p.1). Os padrões inerentes a essas configurações não haviam sido estudados, pois eram considerados sem forma dentro dos parâmetros euclidianos. O autor propõe então o estudo morfológico do amorfo e uma nova geometria da natureza.

O autor sugere o termo fractal a partir do adjetivo latino "fractus" e do verbo "frangere," que significa "quebra" ou "criar fragmentos irregulares". A partir da construção de modelos teórico-matemáticos - sobretudo geométricos - Mandelbrot sugere que a morfogênese de certas configurações naturais amorfas possui regularidade. Essa ordem está implícita não só na complexidade de desdobramento de um padrão, mas na sua qualidade de autossimilaridade escalar. Isso significa que o modo e o "grau de irregularidades e/ou fragmentação são iguais em todas as escalas" (MANDELBROT, 1983, p.1). Com a publicação do livro e subsequente amplos sucesso e influência, biólogos começaram a identificar, por exemplo, padrões fractais em uma série de configurações no corpo humano - na ramificação das artérias e veias; na ramificação dos brônquios, bronquíolos e alvéolos; na rede de neurônios e até no espectro de frequência dos batimentos cardíacos. Leis fractais foram descobertas tanto em fenômenos econômicos, meteorológicos e de dinâmica sísmica, além de sua presença nos mais variados fenômenos da natureza e nas mais variadas escalas. Ao final do século XX, já eram popularizadas fotos evidenciando 
as similaridades entre galáxias e átomos (GLEICK, 1988). A biologia evolucionária e vários outros campos passam a ter que rever o modo como abordam a realidade; as escalas macro e micro passam a ser relativizadas (quanto menor ou maior for a escala, mais complexidade se encontra no universo); o cálculo, a representação e a criação de sistemas complexos é possibilitada pelos computadores; os processos passaram a ter um valor maior que o resultado final, uma vez que a noção de estaticidade é substituída pela de dinamicidade (forma por formação).

Uma das práticas arquitetônicas atuais mais radicais que leva ao limite a noção de "estereometria orgânica", desenvolvida por Mandelbrot, mas lançada por Haeckel no século XIX como um modo de evidenciar uma lei biogenética que desvela semelhanças entre o desenvolvimento morfológico de formas orgânicas e inorgânicas, é a dos arquitetos e programadores alemães Michael Hansmeyer ${ }^{17}$ (1973-) e Benjamin Dillenburger ${ }^{18}$ (1978-). A partir do projeto "Digital Grotesque", de 2013, eles ganharam notoriedade. Trata-se de uma ambiência ornamental imersiva fabricada digitalmente

17. Atualmente é pesquisador do grupo CAAD (Computer Aided Architectural Design) da Swiss Federal Institute of Technology (ETH) em Zurich. Fez a instalação Monolith no Centro de Arte Contemporânea Inhotim, que discute o momento em que a natureza se torna artificial. http://www.michael-hansmeyer.com/ 18. Atualmente é Professor Assistente na John H. Daniels Faculty of Architecture, Landscape and Design da University of Toronto. http://benjamin-dillenburger.com/ 
e projetada a partir de explorações topológicas complexas e estratégias compositivas digitais derivadas de processos puramente geométricos e determinísticos, sem abertura para incorporar elementos ou procedimentos aleatórios. Algoritmos foram utilizados para criar formas que ao mesmo tempo parecem orgânicas e inorgânicas e que pretendem gerar surpresas pela estranheza e complexidade das dobras e redobras. Os padrões tridimensionais gerados seguem um princípio simétrico, mas ao mesmo tempo possuem formas, tamanhos, movimentos e ritmos variados. O espaço foi fabricado com uma tecnologia de impressão aditiva com areia, que é transformada em arenito artificial. A impressão possui uma resolução de um décimo de milímetro e o espaço possui 3,2 metros de altura e cerca de 16 metros quadrados de área. A tecnologia de impressão 3D por si só já possui um potencial enorme e no "Digital Grotesque" foi utilizada de modo impressionante; mas a proposta estética de Hansmeyer e Dillenburger é radical, pois ao levar a ornamentação ao limite do visível e do invisível (da macro à microescala), entre o natural e o artificial (as formas parecem ter surgido de processos naturais de formação e possuem uma plasticidade orgânica que, pelo excesso, tem-se consciência de que são artificiais), entre caos e ordem (o espaço se cria pela transformação de uma dobra em outra dobra, um processo metamórfico fluido que deixa rastro, solidifica-se e evidencia sua formação), a 
percepção é desafiada a decifrar o indecifrável.

Assim, conceitos como autossimilaridade escalar, autopoiesis, emergência e dinâmicas não-lineares, evidentes nos vários campos que permeiam a teoria da complexidade,

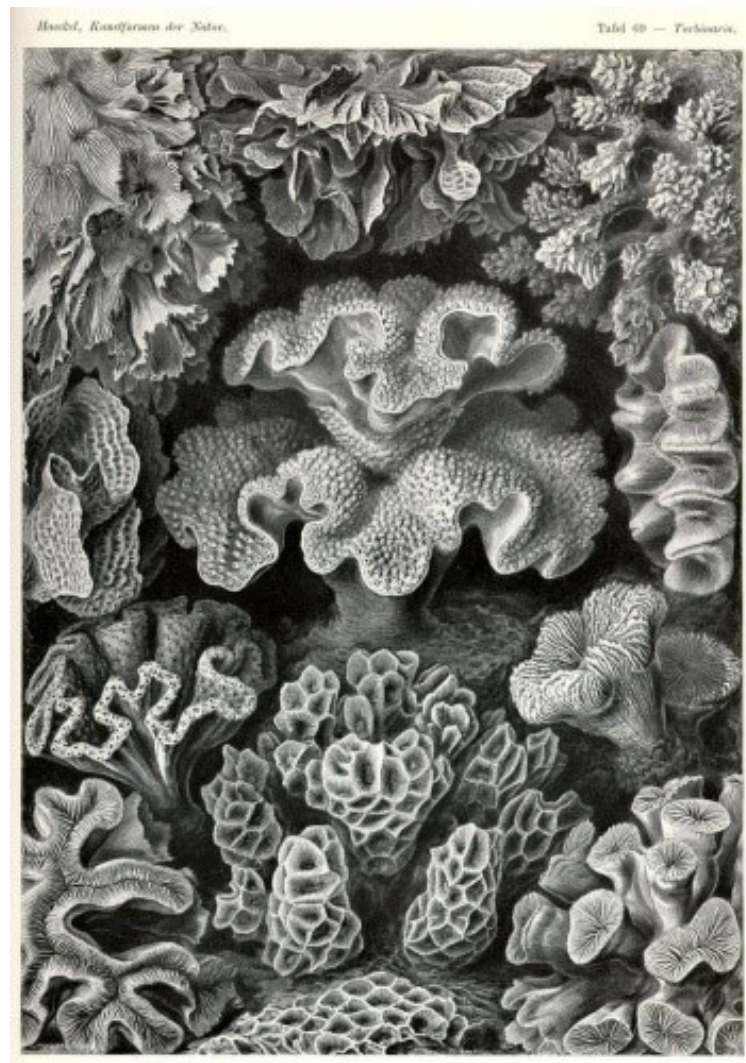

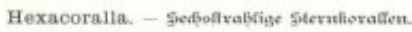

Figura 9 - Corais. Gravura de Ernst Haeckel em "Kunstformen der Natur" (1904). Fonte: HAECKEL, 2012.

20. Cf. duas edições da AD, uma editada por Marcos Cruz e Steve Pike: "Neoplasmatic Architecture," vol. 78, no. 6, 2008; e outra por Neil Spiller e Rachel Armstrong: "Protocell Architecture," vol. 81, no. 2, 2011. 


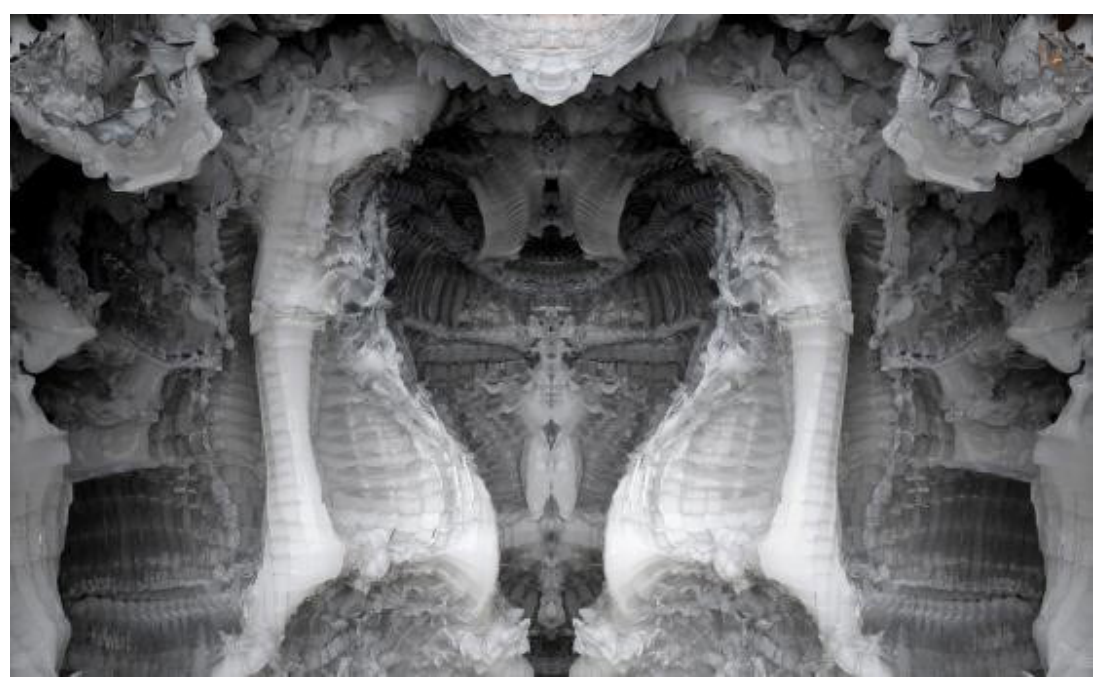

Figura 10 - Um dos experimentos do projeto Digital Grotesque. Fonte: http:// www. digital-grotesque.com/

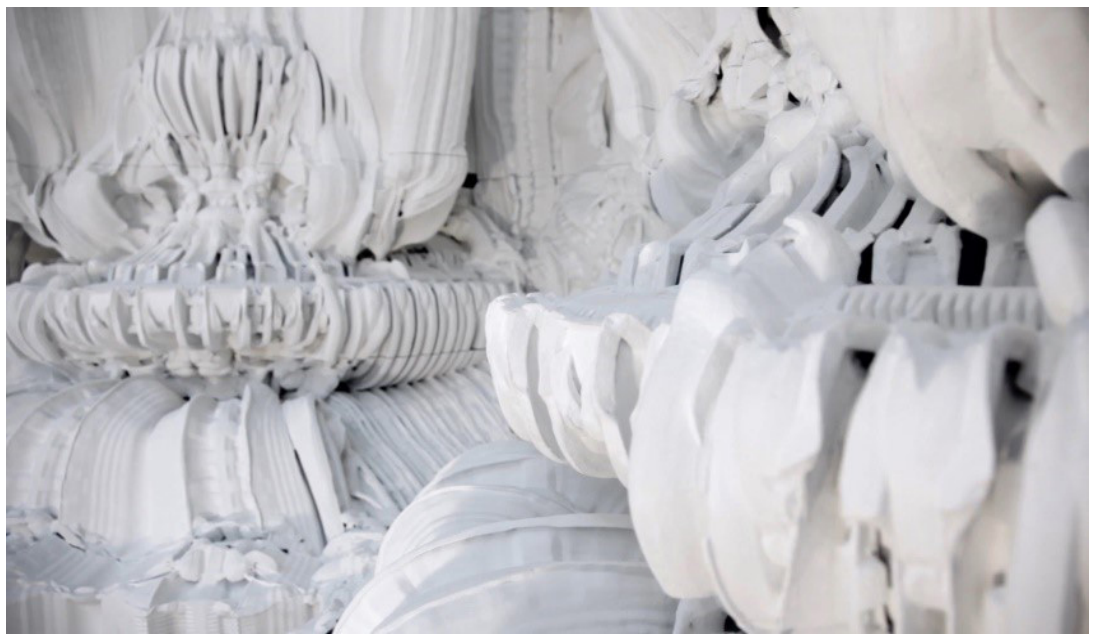

Figura 11 - Detalhe ornamental intrincado. Fonte: http://www.digital-grotesque. $\mathrm{com} /$ 


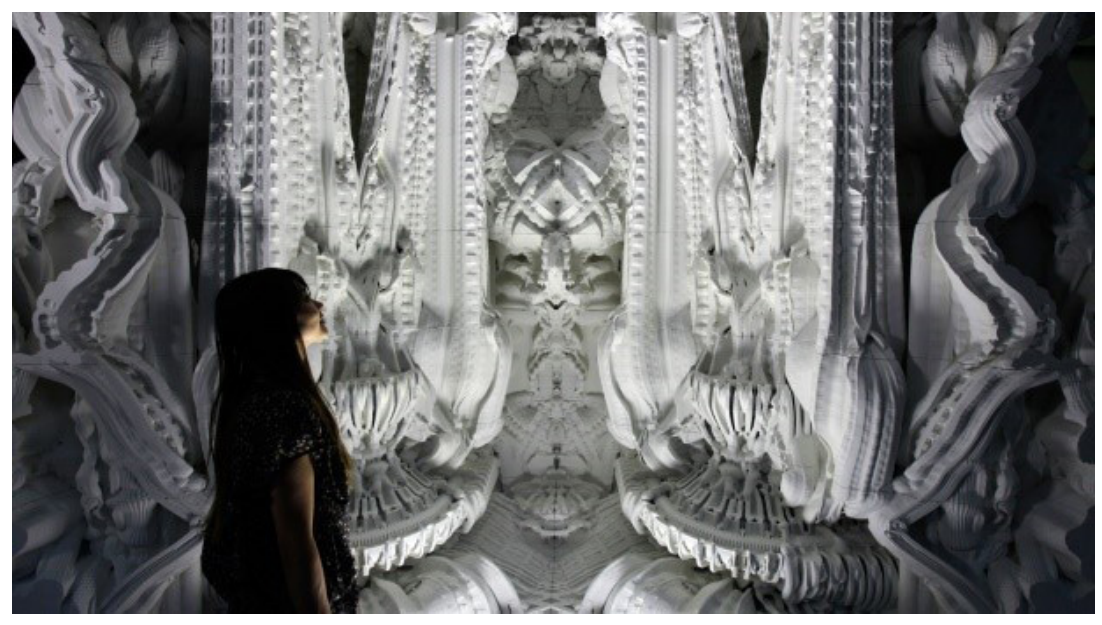

Figura 12 - Imagem que mostra a escala do espaço. Fonte: http://www.digitalgrotesque.com/

têm sido base para investigações de diversos arquitetos e artistas, não só na vertente biomimética ${ }^{19}$ atual, mas recentemente na convergência de suas práticas com a biotecnologia, em especial para a confecção de materialidades bio-sintéticas, em que se pretende a hibridização entre o natural e o artificial. Esse tipo de arquitetura tem sido chamado de "Protocell Architecture" 20. O complexo natureza-ornamento toma dimensões impensáveis, cujos limites estão desconhecidos.

19. Cf. Janine Benyus: "Biomimicry: innovation inspired by nature,"1997. Cf. as duas edições da AD (Architectural Design) editadas por Michael Hensel, Achim Menges e Michael Weinstock: "Emergence: Morphogenetic Design Strategies," vol. 74, no. 3, 2004; e "Techniques and Tecnologies in Morphogenetic Design," vol. 76, no. 2, 2006. 


\section{Conclusão}

Este ensaio teve como pressuposto uma "condição ornamental" para a arquitetura atual e refere-se à natureza do novo panorama que se instala na contemporaneidade que, mesmo com toda sua diversidade, suas limitações e seus potenciais, constitui um momento chave na história recente; é a supremacia do intrincado, do voluptuoso, do exuberante. Esse panorama em expansão demanda um chamado para a reflexão crítica sobre que condição que se quer para o ornamento.

O que une as práticas e o Art Nouveau é o conceito de padrão inerente aos processos e configurações formais da natureza: as operações de analogia, repetição, variação e diferenciação, embutidas na sua lógica, são seus fundamentos. A necessidade de reconhecimento de padrões naturais é algo intrínseco à percepção humana e pertence a uma longa tradição de descrição e representação da natureza pela filosofia, pela arte e pela ciência. Portanto, faz-se necessário simultaneamente recuar em direção às bases e fundamentos do ornamento histórico e avançar em uma agenda para o ornamento contemporâneo, que deve contemplar, a nosso ver, a natureza para além das dimensões do paramétrico-matemático e do tecno-científico.

É próprio do mecanismo da percepção a construção de significado. Isso significa que as figuras não têm escapatória, 
elas serão imbuídas de dimensões simbólicas. Talvez o ornamental, a abertura para o sensível e o simbólico, seja a mesma natureza da arquitetura. Se o ornamento é imbricado na arquitetura, assim também o é a arte: uma epistemologia contemporânea para a arquitetura deve ter a arte como contrabalanceamento da ciência; na verdade, para essas intenções tomarem corpo e haver embrenhamento, somente uma epistemologia das práticas espaciais e do sensível conseguirão atravessar o cientificismo racionalista e acessar a natureza por outras vias.

\section{Referências}

ARMSTRONG, Rachel (ed.); SPILLER, Neil (ed.) Protocell Architecture. London: Wiley, Architectural Design Magazine, vo. 81, n.2, march/ april 2011.

BASSEGODA, Joan Nonell. Gaudí o espacio, luz y equilibrio. Madrid: Criterio, 2002.

BEESLEY, Philip; BONNEMAISON, Sarah. On Growth and Form: Organic Architecture and Beyond. Dalhousie University: Tuns Press and Riverside Architectural Press, 2008.

BERGÓS, Joan. Gaudí: L'home i L'obra. Barcelona: Ariel, 1954. 180p.

BINET, René; PROCTOR, Robert; BREIDBACH, Olaf. From nature to form. Munique: Prestel, 2007. 96p.

BLOOMER, Kent. The Nature of Ornament: Rhythm and Metamorphosis in Architecture. New York: W. W. Norton \& Company, 2000. 240p.

BRUNET, Cesar Martinell. Conversas com Gaudí. São Paulo: Perspectiva, 2007. 216p.

BUSH-BROWN, Albert. Louis Sullivan. New York: George Braziller, 
1960. 128p.

CASANELLES, Eusebi. Antonio Gaudi: A Reappraisal. London: Studio Vista, 1967. 256p.

CHU, Carl S. A metafísica da arquitetura genética e da computação. In SYKES, Krista (org.). O campo ampliado da arquitetura: Antologia teórica 1993-2009. São Paulo: Cosac Naify, 2013. p.322-330. Tradução de Denise Bottmann.

CLAYTON, Philip (ed.); DAVIES, Paul (ed.). The Re-Emergence of Emergence: The Emergentist Hypothesis from Science to Religion. Oxford: Oxford University Press, 2006. 330p.

COLLETTI, Marjan (ed.). Exuberance: New Virtuosity in Contemporary Architecture. London: Wiley, Architectural Design Magazine, vo. 80, n.2, march/april 2010.

CRUZ, Marcos; COLLETTI, Marjan. The return of the figural. 2010. Disponível em http://marcoscruzarchitect.blogspot.com.br/2010/12/ return-of-figural.html

FAHR-BECKER, Gabriele. Art Nouveau. Postdam: h.f.ullman, 2012. 425p.

FOCILLON, Henri. The Life of Forms in Art. New York: Zone Books, 1992. 190p.

GREENHALGH, Paul. Art Nouveau: 1890-1914. New York: Harry N. Abrams, Inc, 2000. 496p.

HEACKEL, Ernst; BREIDBACH, Olaf; HARTMANN, Richard. Art Forms in Nature: The Prints of Ernst Haeckel. Munich: Prestel, 2012. 139p. $2^{a}$ edição.

HEACKEL, Ernst; BREIDBACH, Olaf. Art Forms from the Ocean: The Radiolarian Atlas of 1862. Munich: Prestel, 2013. s/p.

HENSBERGEN, Gijs van. Gaudí: a biography. New York: Perennial, 2003. 322p.

JONES, Owen. A gramática do ornamento: ilustrado com exemplos 
de diversos estilos de ornamento. São Paulo: Editora SENAC , 2010. $504 p$.

LEACH, Neil. Digital Morphogenesis. In PUGLISI, Luigi Prestinenza. Theoretical Meltdown. AD - Architectural Design, v. 71, n.1, 2009. p.33-37.

LEVIT, Robert. Contemporary Ornament: The Return of the Symbolic Repressed. Harvard Design Magazine, Spring/Summer 2008, n. 28. 2008. p.1-8.

LOOS, Adolf. Ornamento e crime. Lisboa: Cotovia, 2004. 279 p.

MANDELBROT, Benoit. The fractal geometry of nature. New York: W. H. Freeman and company, 1983.

MUSEU DE ARTE DE SÃO PAULO. Antoni Gaudí (1852-1926). São Paulo: MASP, 1988. 281p.

MOUSSAVI, Farshid (ed.); KUBO, Michael (ed.). The function of ornament. Barcelona: Actar, 2008. s/p.

PAIM, Gilberto. A Beleza sob Suspeita: o ornamento em Ruskin, Lloyd Wright, Loos, Le Corbusier e outros. Rio de Janeiro: Jorge Zahar Editor, 2000. 147p.

PANE, Roberto. Nova contribuição ao estudo de Gaudí entre a crítica de arte e a psicologia. In MUSEU DE ARTE DE SÃO PAULO. Antoni Gaudí (1852-1926). São Paulo: MASP, 1988. p.16-35.

PAYNE, Alina (ed.); NECIPOGLU, Gulru (ed.) et al. Histories of Ornament: From Global to Local. Princeton, New Jersey: Princeton University Press, 2016. 453p.

PEVSNER, Nikolaus. Origens da Arquitetura Moderna e do Design. São Paulo: Martins Fontes, 2010. 224p. Tradução de Luiz Raul Machado. PICON, Antoine. Digital Culture in Architecture: an introduction for the design professions. Basel: Birkhauser, 2010. 224p.

Ornament: The politics of Architecture and Subjectivity. Chichester: John Wiley \& Sons, 2013. 168p. 
RIEGL, Alois. Problems of style: foundations for a history of ornament. Princeton, New Jersey: Princeton University Press, 1992. 406p. Tradução para o ingles de Evelyn Kain.

RODRIGUES, José Manuel at al (org.). Teoria e Crítica de Arquitectura - Século XX. Lisboa: OASRS, 2010. 1022p.

RUSKIN, John. Modern Painters: Part IV. New York: John Wiley, 1863. $421 \mathrm{p}$.

$222 p$.

The Seven Lamps of Architecture. New York: Dover, 1989.

Selections From the Works of John Ruskin. Cambridge, Massachusetts: The Riverside Press, 2012. 286p. Kindle Edition.

SEMPER, Gottfried. The Four Elements of Architecture and other writings. Cambridge, UK: Cambridge University Press, 2010. 314p. Tradução de Harry F. Mallgrave e Wolfgang Herrmann.

SCHUMACHER, Patrik. The Autopoiesis of Architecture: A New framework for architecure. London: Wiley, 2011. Vol.1. 461p.

The Autopoiesis of Architecture: A New Agenda for architecure. London: Wiley, 2012. Vol.2. 774p.

SPUYBROEK, Lars. The Sympathy of Things: Ruskin and the Ecology of Design. Rotterdam: V2_Publishing, 2011. 400p.

WEINSTOCK, Michael. The Architecture of Emergence: Evolution of Form in Nature and Civilisation. London: Wiley, 2010.

WHITEHEAD, Alfred North. The concept of nature. Project Gutenberg Ebook, 2006. Ebook n. 18835.

WORRINGER, Wilhelm. Form Problems of the Gothic. New York: G. E. Stechert \& Co., 1920. Edição: Authorized American Edition. 146p.

Abstraction and Empathy: A Contribution to the Psychology of Style. Chicago: Ivan R. Dee, 1997. 144p.

WRIGHT, Frank Lloyd. Em defesa da arquitetura, 1908. In RODRIGUES, José Manuel at al. Teoria e Crítica de Arquitectura - Século XX. Lis- 
boa: OASRS, 2010a. p.50-60.

ZERBST, Rainer. Gaudí: Obra Arquitectónica Completa. Köln: Taschen, 2005. 239p. Tradução: Casa das Línguas, Lda. Tradução: Alberto Marsicano.

Recebido em: 20/02/2016

Aprovado em: 02/12/2016 